\title{
The Pressure for Euthanasia In Medically Developed Countries
}

\author{
Eleanor Flynn \\ Selection Lead and Coordinator, Aged Care Rotation, Department of Medical Education, Melbourne \\ Medical School, Melbourne. \\ Corresponding Author: Eleanor Flynn \\ Email-e.flynn@unimelb.edu.au
}

I write this from the state of Victoria in Australia which has recently enacted a law permitting both physician assisted suicide and euthanasia for people over 18 who are competent to make decisions. They must be suffering from an incurable illness, which causes intolerable suffering, and be expected to live for less than six months.

In attempting to understand why this legislation succeeded I have considered the many factors I think play a part in why this decision was made now and present them to provide some background for the discussions which will arise in many other jurisdictions over time.

The most important reason why individuals actively request euthanasia which isn't covered in the current Victorian, or most other similar, legislation is existential distress, loss of dignity, loss of control, and concern about future loss of dignity and control. These are the four principal reasons why people request euthanasia. Those requesting euthanasia for themselves rarely cite unbearable physical suffering or pain as the reason, though these latter issues are the reasons that advocates provide in the need for euthanasia, and they appear in all the legislation. The people who request euthanasia are concerned that they are, or will soon be, no longer autonomous beings and must rely on others to provide care and support. As an Occupational Therapist colleague of mine suggested people request euthanasia when they can no longer manage their personal toileting. This may seem to trivialize the issue; however, it is very real and accounts for people travelling to Switzerland for physician assisted suicide because they fear the consequences of age or disease, which will leave them relying on other people for their personal care needs.

I think there are several specific reasons why the push for the legislation came in Victoria at this time. There are some more general concerns that also lead to a decision to support euthanasia. However, those who have been driving the need for such legislation will often not be aware that these issues underpin their thinking.

Main Drivers for the Legislation, knowledge of the dying process and decrease in religious belief There are three main drivers In the Australian context; the unfamiliarity of many people with the dying process, the concern about unnecessary medical treatment at the end of life, and the marked decrease in religious belief.

In Australia currently, the average age of death is 82 , which means that many people in their forties and fifties and even sixties may not have experienced the death of close relatives or friends and so their only frame of reference is the media. In news reports death is often sudden and violent and either one of a "tragic case of a young person taken too early" or reports of war or environmental disasters killing large numbers of people in other parts of the world. While films and television dramas also include sudden violent deaths, there are also deaths from disease. However, in these cases the death is usually portrayed as peaceful and relatively quick, in that the person dies within one episode of a TV drama or within less than a quarter of a film. Even in 
opera the person who dies is usually singing a long aria as she does so. Australian doctors, especially those working in Palliative Care, General Medicine, General Practice or Geriatrics, know that death is a process and many people die slowly over a period of days, sometimes up to two weeks and we know this is normal.

The lack of understanding of this as normal leads the family members in these situations to consider that their relative had a "bad death" and was suffering for many days and should have been able to be "put out of their misery" by medical intervention. As a counterpoint to this, though also part of the same lack of experience of dying for old persons, there are the concerns of family members that old people will be needlessly resuscitated in hospitals. This becomes a problem when no one has had a conversation with the older person, or their next of kin, about what they really want when they are close to death. Many older people accept that they are dying. They do not want to be resuscitated again and again from pneumonia, which used to be the old person's friend. Doctors will insist on resuscitation only when there is no information about what the patient wants. Often this occurs because there has been no discussion with the person or family before a medical crisis, so the old person is taken to the emergency department.

As well as these concerns by family members there has been a marked decrease in religious belief in the traditional Christian churches so that in the last Australian census the majority of people claim to have no religious belief. While the number of migrants from the Indian subcontinent, China, Taiwan and countries where Islam is the majority religion are increasing these numbers are still too small to have a major effect on the reported religious beliefs of the nation. Although the religions of the Book; Judaism, Christianity and Islam, consider that euthanasia is unjustified killing, some Christians and Jews in educationally and medically developed regions now consider that it is permissible in certain circumstances, though their leaders preach against it. The decrease in religious belief and practice means that more people are likely to consider euthanasia on its merits as a philosophical issue rather than considering whether there are any religious concerns. This change suggests that possibly more people would support legislation change and possibly engage with it themselves more than would have been the case thirty years ago.

\section{Social, Cultural and Environmental Issues}

When considering the more general issues that might be relevant to a discussion about death and dying and euthanasia the following points are also probably partially relevant for the recent Victorian decision though perhaps less obviously. These factors are family disconnections, our connectivity to everything, and the change to a client relationship from a doctor patient one.

1. As we know across the world there is an enormous movement of people, so that what began with organized migration to Western countries continues along with the flow of refugees to these and other countries. These movements lead to increasing disconnection between the generations due to the fracture of families, added to by divorce. So, when an older person is dying not only are there are less people immediately available to be present but also there are no longer the same shared events and memories to use in conversation with them as they transition towards death. So, the lack of connection means awkward conversations and an unwillingness to spend time with a relatively unknown person. This is not an issue that will arise in philosophical discussions about euthanasia however it is part of the background.

2. This may be related to the fourth point, our expectation that things are happening all the time plus a terror of being bored. As we spend more and more of our time checking our digital devices for news and updates we expect new things all the time and we have lost the ability to relax and engage in a situation where there is minimal stimulation. We dread being bored or being in a situation where we don't know what to say, when in fact the situation may not require us to say anything very much, just to listen and be with people. 
3. A further issue is the change in medically and educationally developed regions from a doctor patient relationship to a client relationship where the client requests treatment of a doctor and often appears with "evidence" from an internet search. This flattening of the doctor patient hierarchy is generally a very good thing, allowing persons with medical problems to learn about the causes and management of their diseases and improve their health by being actively involved in their management. The problems arise when the "patient" no longer accepts anything the doctor says as expert and prefers opinion from other sources to the evidence that the doctor is providing from years of study and experience. People from countries with flatter democratic structures are particularly likely to consider that they are as knowledgeable as the experts and to demand that they can have whatever they request.

The predominance of Baby Boomers, people born in the 1950s and early 1960s, in senior political and management positions may encourage this client mindset. This group of people in developed regions have always got whatever they want, currently have better health than their parents at this age and are able to use the available resources, including the internet, to decide how they want to manage their lives. They do not want pain or suffering, or indeed ageing. So, as all groups do, they assume that everyone is like them and will want what they want, and in this situation, they have the political and organizational power to make things happen.

\section{Conclusion}

I consider that some or all of these various issues have been relevant in the decision that the Victorian parliament took in 2017 to legalize euthanasia and physician assisted suicide. I am sure that those who lobbied do not think that any of these issues were important in their thinking because they considered that they were advocating for people to be freed from suffering. However, it may be that they were advocating for suffering that they did not want to watch, not suffering that people undergoing it were clamoring for relief. It also moves away from the philosophy of palliative care to kill the suffering not the sufferer. Once we reduce the decision to a rights issue it becomes a consumer issue, one where the person can demand of their doctor that their life be ended because they don't want the suffering which might occur in the future.

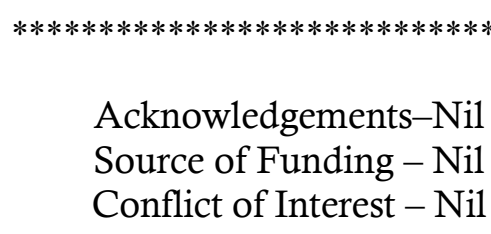

